\title{
Teorias sobre voz nas décadas de 1960 e 1970 e cinema contemporâneo
}

\section{Fernando Morais da Costa}

Professor do Departamento de Cinema e Vídeo e do Programa de Pós-Graduação em Cinema e Audiovisual (PPGCine) da Universidade Federal Fluminense.

E-mail: fmorais29@terra.com.br
Resumo: A partir da recente redescoberta de determinados textos sobre voz escritos no decorrer das décadas de 1960 e 1970 por Derrida, Barthes e pelo menos evidente mas central para esta comunicação, Don Ihde, propomos, ao mesmo tempo em que fazemos a aproximação de diferentes campos com o cinema, a seguinte questão: o que tais trabalhos, conhecidos, antigos, mas recentemente reeditados, podem acrescentar ao que pensamos sobre som no cinema contemporâneo?

Palavras-chave: Voz; Cinema Contemporâneo; Silêncio; Grão.

Theory on voice in the decades of 1960 and 1970 and contemporary cinema

Abstract: Due to the recent republishing of three works on voice written among the decades of 1960 and 1970 by Roland Barthes, Jacques Derrida and by the less evident, but fundamental for this paper, Don Ihde, we ask, by bringing together concepts from different areas inside the cinema, the following question: how can those works, somehow ancient but recently republished, contribute to our conception of voices and sound in contemporary cinema?

Keywords: Voice; Contemporary Cinema; Silence; Grain. 
${ }^{1}$ Entre as pesquisas recentes no Brasil sobre voz no cinema, gostaríamos de destacar uma que faz interface com esta pesquisa: a dissertação defendida, em 2017, por Debora Regina Taño, intitulada Sonoridades vocais no cinema: a fala flutuante em "Família rodante" (2004), de Pablo Trapero, na Universidade Federal de São Carlos. Sobre a relação entre a dissertação e este artigo, as referências bibliográficas compartilhadas estabeleceram um circuito frutífero entre falas e textos escritos.
Este artigo procura analisar três textos, ao mesmo tempo conhecidos, antigos e recentemente reeditados, para pensar aplicações possíveis no cinema quanto a seus modos de pensar a voz. Antes de entrar nos textos propriamente, cabe explicar alguns pontos.

Os textos são: O grão da voz, de Roland Barthes; "A voz que guarda silêncio", de Jacques Derrida, capítulo de $A$ voz e o fenômeno; e Listening and voice, de Don Ihde. Nenhum dos três é sobre cinema. A partir dessa afirmação, há uma explicação que se bifurca. Em primeiro lugar, sigo achando necessário buscar a interdisciplinaridade, ao mesmo tempo comum à teoria do cinema em específico e à teoria da comunicação no geral. Trata-se de um movimento consciente vindo de um pesquisador que foi formado dentro do entendimento de que o cinema tem uma forma de expressão específica, e que, por conseguinte, proporciona uma reflexão particular, embora essa consciência não invalide a porosidade entre áreas diversas e as possíveis aplicações de seus conceitos sobre esse mesmo cinema. Para este pesquisador, por mais que as áreas se subdividam, ganhem autonomia - e o cinema também passa por esse processo - a interdisciplinaridade é uma forma de pensar compulsória, obrigatória. A outra parte da bifurcação tem o intuito de explicar que para este texto a aplicação ainda tem apenas a forma de uma proposta. Não haverá nestas próximas páginas análise fílmica. Esta é, portanto, uma revisão de conceitos que julgamos pertinentes à análise da voz no cinema. O recorte da voz, dentre o universo de sons de um dado filme, faz parte de um projeto de pesquisa que tem tido como parte de seus resultados artigos e palestras recentes. Neste momento, julgamos importante, a partir de leituras advindas de áreas de conhecimento variadas, fazer um intervalo na análise fílmica e determo-nos aos textos escritos em $\mathrm{si}^{1}$.

Devemos ainda explicar que o encontro recente com os três textos, que dá corpo diretamente a esta reflexão em forma de artigo, foi proporcionado pela reedição de todos eles em língua inglesa. Dos três, dois foram produzidos originalmente em francês - casos de Barthes e Derrida - e um em inglês, nos Estados Unidos - caso de Ihde. Tanto O grão da voz quanto $A$ voz e o fenômeno-e, dentro dele, o capítulo "A voz que guarda silêncio", a única parte do livro sobre a qual trabalharemos - são conhecidos em português, por suas traduções no Brasil e em Portugal. Listening and voice, de Don Ihde, não. A partir de esforços editoriais norte-americanos e ingleses, os três textos voltam a ser lidos e discutidos neste momento. Um dos intuitos deste artigo é trazer a discussão para o âmbito brasileiro dos estudos de cinema, com um recorte sobre os estudos do som fílmico e, mais especificamente, sobre voz.

Antes de nos determos sobre os textos, podemos resumir as particularidades de cada um. Em $O$ grão da voz, Barthes propõe a metáfora do grão em busca das especificidades em cada voz. No caso desse texto, Barthes analisa o canto, a palavra cantada por duas diferentes vozes, com objetivo de propor uma análise da voz que extrapole o campo semântico. Uma análise que entenda o que há em uma voz cantada para além do sentido majoritariamente linguístico. Em 1973, Derrida encontraria uma possível relação entre voz e silêncio, que nos interessa como objeto de pesquisa, tendo como base teórica a fenomenologia de Husserl. Questões de fundo para Derrida são, por exemplo, a possível compreensão da voz como uma espécie de signo ideal versus a materialidade de sua presença a cada vez que ela se manifesta. Tocaremos nesse problema para redigir uma possível crítica.

O texto que mais nos interessa talvez seja o menos conhecido dos três, dado o peso que Roland Barthes e Jacques Derrida têm para áreas diversas entre si, como as ciências sociais, a comunicação e a filosofia. Publicado em 1976, Listening and voice: phenomenologies of sound, de Don Ihde, também se ancora na fenomenologia, em Husserl e Heidegger, como o título já deixa ver. É a partir de Husserl que Ihde propõe uma filosofia da escuta e da voz. O autor justifica a escolha da voz como objeto pela centralidade da palavra falada e de sua 
escuta para a nossa percepção. A ideia da centralidade e das zonas que the são complementares, horizontes, limites, dão forma à metodologia a partir da qual o autor cerca seu objeto. Para ele, a palavra falada é um centro possível para o sentido, mas a apreensão desse sentido passa pela complexa personificação dessa voz, pela presença de um corpo, com tudo que ele seja capaz de manifestar. Nesse sentido, Ihde se aproxima do que seria desenvolvido de forma extensa por Paul Zumthor, como já discutimos em texto anterior (ZUMTHOR, 1993). Para Ihde, a palavra pode parecer o centro do sentido, mas no centro da palavra está o som em si, a respiração mesma. De forma complementar, o silêncio seria para a palavra falada o limite, o horizonte, a extensão possível do sentido. Uma filosofia da escuta deveria, segundo Ihde, levar em conta o que está ao mesmo tempo entre as palavras, abaixo e acima delas, o que as circunda.

Ao propor uma fenomenologia da voz, dentro de uma filosofia da escuta, achamos especialmente relevante o fato de Ihde ser claro ao dizer que não põe em prática tal filosofia para combater necessariamente um aferível ocularcentrismo no campo da filosofia nos anos 1970, mas sim para entender o que se sobrepõe entre a percepção ocular e a percepção auditiva. Seu objetivo seria analisar quais zonas de intercessão podem existir entre ambas. Essa noção de complementaridade entre as zonas de percepção auditiva e visual nos parece fundamental para uma compreensão justa de um fenômeno audiovisual. Podemos mesmo dizer aqui que nunca, nos estudos de som no cinema que transformamos em nosso trabalho cotidiano, pensamos em nada diferente de uma relação que nos parecesse justa entre as potencialidades dos dois reinos, o sonoro e o visual.

\section{Barthes, o grão}

Comecemos por Barthes. O grão da voz é um texto curto, como tantos outros do autor, cuja densidade da argumentação pode parecer desproporcional à extensão do texto. Escrito na década de 1960, o ensaio ganharia tradução para o inglês

${ }^{2}$ Tratamos aqui do ensaio em si. Dentro da obra fragmentada de Barthes, por muitas vezes, as republicações confundem a própria procura pelos textos. O grão da voz, por exemplo, para além de dar nome ao artigo, seria ainda, em francês, inglês e português, o título de uma coletânea, cuja publicação em francês data de 1981. na década seguinte e, na sequência, para o português². Barthes inicia dizendo que a análise linguística da música já propõe um problema em si: seria o caso de um sistema semiótico analisando o outro. Com a preocupação de produzir uma análise justa da música, ele propõe uma recusa do que lhe parece um usual excesso de uso dos adjetivos, insuficientes para comunicar o que acontece em um fenômeno musical. Uma vez eleita a música como objeto, o recorte recai sobre a música vocal, o canto. Para ele, uma melodia cantada é o local em que se materializa o encontro entre a linguagem e uma voz. Para estabelecer a metáfora que traduz esse encontro, Barthes concretiza a fuga aos adjetivos pela escolha de um substantivo: grão. Haveria algo nessa produção dupla de música e linguagem que é central, básica, específica, um grão da voz (BARTHES, 2012: 505)

Para dar forma à argumentação de que há algo específico em cada voz que se materializa durante o canto, Barthes compara as vozes de dois cantores líricos conhecidos, que, segundo ele, além de serem divergentes para o seu gosto pessoal, divergem no modo como materializam, dão forma, às canções que interpretam.

Os dois cantores escolhidos são Charles Panzéra, barítono suíço, renomado a partir da década de 1920, e Dietrich Fischer-Dieskau, barítono alemão também famoso, mas em um momento posterior do século XX, nascido décadas depois do primeiro. Fischer-Dieskau é reconhecido, por exemplo, por suas interpretações das lieder, de Schubert, e das Kindertotenlieder, de Mahler. Der Doppelgänger, de Schubert, também conta com gravação célebre de Panzera. A repetição do repertório em dois barítonos com os óbvios registros vocais próximos, ainda que gerando cantos tão diferentes, é a condição a partir da qual a ideia do grão, da particularidade aferível em cada voz, pode ser percebida.

Antes da análise comparativa entre os dois barítonos, Barthes ainda comenta as vozes graves dos baixos russos, para dar um exemplo de como o corpo precisa ser 
entendido como a âncora a partir da qual se deve pensar uma voz. Ao ouvir essas vozes há que se perceber como elas são projetadas pelas cavidades do corpo, pelos músculos que vibram às suas passagens, e como a postura fálica, ereta, dos cantores possibilita aquelas emanações. "O grão é isso, a materialidade do corpo falando sua língua materna” (BARTHES, 2012: 506)

Sobre os dois barítonos citados mais especificamente, Barthes percebe as radicais diferenças das interpretações, o que se torna ainda mais perceptível dadas as repetições do repertório. Fischer-Dieskau seria um cantor que interpreta as obras emprestando a elas mais dramaticidade, o que se materializa na sua diç̧ão, no emprego das pausas, no soltar e prender da respiração, no demarcar dos tempos a partir desse esforço físico. Barthes comenta que, ao ouvi-lo, tem a impressão de que ouve apenas seus pulmões, não a língua, a passagem do ar pela boca, pelo nariz. Panzera proporcionaria a sensação contrária. O esforço da respiração estaria perfeitamente escondido pela técnica adequada para tal efeito. A emanação da voz seria clara, geraria o efeito de uma redução da expressividade.

Sobre o assunto específico da respiração, do controle do ar como pré-condição para a existência de cada manifestação vocal, voltaremos a falar ainda neste texto, quando estivermos pensando sobre as considerações de Ihde. Mas cabe lembrar também o recente estudo de Davina Quinlivan, The place of breath in cinema. Quinlivan coloca a questão de como representar a respiração, invisível por definição, no audiovisual. Quais indícios levam à materialização do corpo que respira, especialmente quando 0 ato de respirar se torna relevante para determinada passagem no filme? Alinhada a Laura Marks e à sua teoria háptica do cinema, explicando muito brevemente, quando outros sentidos para além da visão e da audição estão em jogo na recepção cinematográfica, via ativação de memórias do espectador a partir de seu contato com o filme, Quinlivan traz um número enorme de filmes nos quais o ato de respirar torna-se fundamental par a identificação entre espectador e personagem, por

${ }^{3}$ Ver Marks (2000). exemplo ${ }^{3}$. Quinlivan faz ainda uma analogia entre o "grão", que analisamos aqui, e Ondas do destino, de Lars von Trier, em que "grão" é entendido como verificável tanto na imagem quanto no som (QUINLIVAN, 2012: 141).

Voltando a Barthes, para estender uma análise que, como vai ficando claro, procura mais na voz do que o mero significado linguístico, ele compara dois momentos em que a morte das personagens é central para as conclusões das obras. São elas Boris Godunov, de Mussorgsky, e Pelléas et Mélisande, de Debussy. Enquanto a morte de Boris é um prodígio de expressão vocal, a de Mélisande se tornaria famosa por ser silenciosa, "morre sem qualquer ruído", como diz Barthes. Essa obra de Debussy é repetidas vezes citada como um exemplo da expressividade do silêncio na música erudita moderna. De resto, nos cabe dizer que a análise comparativa das expressividades possíveis da voz e do silêncio, ainda que na música, vai de encontro ao que nos interessa provar em nossas pesquisas sobre o cinema contemporâneo.

O que nos parece central na análise de Barthes, e que também está em concordância com o que procuramos fazer em nossas considerações sobre a voz no cinema contemporâneo, é a proposta de fazer uma análise da voz que não se restrinja ao que nela há de linguístico. Uma tentativa, nas palavras de Barthes (2012: 507), de "escapar da tirania do significado". Ao perceber sutilezas relacionadas ao timbre, à respiração em si, à relação entre a produção de fonemas e cada idioma, Barthes demarca que isso não faz da ideia do grão uma mera redução ao timbre, ou a outra característica sonora. Ao invés disso, ao absorver camadas de percepção sonora para além do linguístico, sua análise pode redistribuir o peso do significado de cada manifestação vocal, agregando sentido. Evidentemente, tal análise tem como objeto o canto lírico, mas poderia ser facilmente expandida para demais manifestações vocais. Nossa esperança é que possa, de alguma forma, ser aplicada à voz no cinema. 
${ }^{4}$ Na versão em inglês: “The 'grain' is the body in the voice as it sings, the hand as it writes, the limb as it performs. If I perceive the 'grain' in a piece of music and accord this 'grain' a theoretical value (the emergence of the text in the work), I inevitably set up a new scheme of evaluation which will certainly be individual - I am determined to listen to my relation with the body of the man or woman singing or playing and that relation is erotic - but in no way 'subjective' (it is not the psychological 'subject' in me who is listening; the climatic pleasure hoped for is not going to reinforce - to express - that subject but, on the contrary, to lose it)".

${ }^{5} \mathrm{Na}$ tradução para o português. $\mathrm{O}$ original em francês, "La voix et la phénomène", é de 1967. Para este artigo, seguimos a tradução para o inglês, "The voice that keeps silence", capítulo de Speech and phenomena.
O "grão" é o corpo na voz que canta, na mão que escreve, no membro que atua. Se eu percebo o grão em uma peça musical e concedo a esse grão um valor teórico (a emergência do texto na obra), eu inevitavelmente estabeleço um novo esquema avaliativo que certamente será individual - eu estou determinado a escutar a minha relação com o corpo do homem ou da mulher que canta ou toca, e essa relação é erótica - mas de forma alguma subjetiva (não é o "sujeito" psicológico em mim que está escutando; o prazer esperado não reforçará - para expressar - aquele assunto mas, ao contrário, o diminuirá). (BARTHES, 2012: 509, tradução nossa) ${ }^{4}$.

O leitor de Barthes sabe que a atenção ao erotismo não é estranha à sua obra. Assim como não são raras as referências à respiração, à voz, ao canto. Em um texto célebre, e quase paralelo ao Barthes citado enquanto teórico, Fragmentos de um discurso amoroso - que o cinema revisita no momento da escritura deste artigo - seja pelas meditações acerca do amado ausente, seja pela sua presença, há considerações acerca das manifestações vocais. No fragmento "O ausente", que retrabalha, entre outros, $O$ banquete de Platão, o suspirar concretiza "a emoção da ausência" (BARTHES, 2015: 55). Em "A dedicatória", as referências se dividem entre Platão, uma vez mais, e Baudelaire. O objeto de eleição é a declaração cantada: "o canto é o suplemento precioso de uma mensagem vazia, inteiramente contido na sua direção, pois o que dou quando canto é ao mesmo tempo o meu corpo (através da minha voz) e o mutismo com que o condenas" (Ibid.: 101)

\section{Derrida, voz como objeto, ocularcentrismo}

O segundo texto vem da obra de Jacques Derrida. Trata-se do capítulo "A voz que guarda silêncio", de $A$ voz e o fenômeno ${ }^{5}$. Entendemos como uma preocupação central para Derrida, quando ele escolhe a voz como objeto, a necessidade de uma análise, desejável para ele, dos fenômenos como se expressam no "aqui e agora", em oposição à idealização dos signos, prejudicial à análise de base fenomenológica. Para Derrida, uma história da fenomenologia e dos corpos como objetos seria, até aquele momento, inseparável da história da idealização da voz, da fonação.

Assim, entender os poderes de uma dada voz deveria levar em conta um afastamento da metafísica e apostar na presença do objeto em si, na "objetividade do objeto" (DERRIDA, 2012: 495). Para Derrida, o nome desse objeto a partir do qual o analista pode aferir a objetividade de um dado fenômeno no tempo e espaço em que ele acontece é: voz. Uma voz é escutada. Ela não precisa ultrapassar esse simples evento para nos afetar em sua atividade expressiva, defende ele.

O que nos cabe criticar é a dificuldade assumida por Derrida para perpetrar uma análise do valor fenomenológico de uma voz, uma vez que, segundo ele próprio, um fonema seria "o mais ideal dos signos" (Ibid.: 497). Para ele, o fato de a voz ser escutada pelo próprio sujeito enquanto fala propõe o problema da autoafecção. Grosso modo, ouvir-se enquanto se fala põe em ação a idealização da própria voz.

Jonathan Sterne, em The audible past, descreveu o que chamou de litanias entre os estudos de imagem e som, dentro dos quais o som e a audição são sempre tidos como menos objetivos do que a imagem e a visão. A audição tenderia, por exemplo, à subjetividade, enquanto a visão, à objetividade; a audição seria prioritariamente temporal, a visão, espacial; a audição seria omnidirecional, a visão, direcional; a audição proporia a imersão do sujeito, a visão ofereceria a perspectiva; a audição levaria ao afeto, a visão, ao intelecto. Sterne elenca uma série de binarismos, estes que citamos e outros, aferíveis na história dos estudos da percepção, e diagnostica que tais dicotomias tendem a sempre relegar o som e a audição à condição de serem objetos de difícil análise, mais obscuros e exóticos do que a imagem e a visão. Os estudos de som não teriam nada a ganhar a partir das pressuposições que tratam seus objetos como difíceis, estranhos, misteriosos (STERNE, 2003: 15). 
${ }^{6}$ Para considerações acerca do ocularcentrismo, ver, por exemplo, Modernity and the hegemony of vision, organizado por Levin (1993), em especial o capítulo Ocularcentrism and social criticism, de Georgia Warnke (p. 287-308).
Tendemos a concordar com o argumento de Sterne e, com alguma surpresa, percebemos em Derrida o interesse pela voz como objeto relevante para a fenomenologia ao mesmo tempo em que se repete, mesmo ali, a ideia do objeto difícil, "o mais ideal dos signos", em suas palavras. Derrida não fugiria assim do ocularcentrismo verificável em uma série enorme de momentos da história da filosofia, presente inclusive na segunda metade do século $X X$, dentro da qual sua obra se insere ${ }^{6}$.

Derrida cita a influência de Edmund Husserl sobre seu trabalho, o Husserl de Origens da geometria e de Meditações cartesianas, trabalhos tardios do filósofo alemão. Dali, Derrida retira, por exemplo, a preocupação com o que seria uma redução que a linguagem precisa fazer para traduzir a experiência. A tradução para a linguagem limitaria o que de fato acontece, configurando um segundo extrato da experiência em si. Haveria, portanto, um momento primal, pré-expressivo, da produção de sentido (DERRIDA, 2012: 499).

Tangenciando ainda a autoafecção, majoritariamente identificada como produtora de um problema em potencial, tendemos a achar que Barthes resolve de forma menos problemática a relação entre a análise e o prazer da audição, ainda que Barthes se refira à audição das vozes de outros. São fenômenos diferentes, sabemos, mas percebemos em Derrida uma necessidade de distanciamento da voz que para Barthes seria menos relevante. Há, em Barthes, o prazer confesso da audição, mas ele não diminuiria a potência da análise. Reverberaria em Derrida um distanciamento dos prazeres dos sentidos, no geral, e da audição, no particular, que também faz parte de uma tradição da filosofia, como, por exemplo no Kierkegaard de Diário de um sedutor, Temor e tremor, $O$ desespero humano. Sobre o silêncio em Derrida, nos parece que ele surge apenas como metáfora, como o sentido que as palavras falhariam em completar.

\section{Ihde, voz como centro, silêncio como horizonte}

O terceiro texto, o menos conhecido, mas central para este trabalho, é Listening and voice, phenomenologies on sound, de Don Ihde. Também reeditado recentemente, tem sua primeira publicação em 1976, embora a tese que originou o livro seja da década anterior. Como o título já mostra, Ihde também insere a voz como objeto no domínio da fenomenologia, trazendo como referência central o mesmo Husserl, e até mesmo o exato Meditações cartesianas, citado por Derrida. Ihde dialoga ainda com o Maurice Merleau-Ponty, de Fenomenologia da percepção e de $O$ visível e o invisível, com o Martin Heidegger, de Ser e tempo, e com o Sartre, de $O$ ser e o nada e $A$ imaginação.

Ihde justifica a escolha de seu objeto pela importância que a escuta da palavra falada exerce na nossa percepção diária, pela centralidade de sua presença. Ele comenta a dificuldade de estudar um fenômeno que demanda a interseção entre tantas disciplinas: acústica, psicologia, linguística, musicologia, entre outras. Lembra ainda a centralidade da palavra falada e ouvida cotidianamente para o ser humano, e nota que a base da palavra está na respiração - mais uma vez ela - sua ação como pré-condição para a emissão de qualquer som vocal. Ihde recorre a pensadores tão distantes como Anaximenes para citar o paradoxo da invisibilidade do ar e da respiração como condição primal para produzir algo, ainda que também invisível, tão marcante para a percepção: uma voz (IHDE, 2007: 13).

Ihde defende que o filósofo que faz da fenomenologia a ramificação pela qual seu método faz sentido não pode esquecer que uma voz é um fenômeno sonoro. É a partir do entendimento de que uma voz é, antes de tudo, um som que o filosofo pode se preocupar com a significação de um fenômeno sonoro quando ele é vocal. Notamos aqui a mesma intenção que partilhamos, de perceber uma voz para além do seu teor semântico já identificada em Barthes. 
Em adição à justificativa da voz como objeto, Ihde lembra que o século XX assistiu, como seguimos assistindo, uma ampliação da faixa de frequências audíveis, não em nossos ouvidos diretamente, já que não são capazes disso, mas dos usos variados de frequências abaixo e acima do limite da audição humana, para procedimentos científicos que fazem cada vez mais parte de nosso cotidiano: infrassons, ultrassons. Notamos, sobre isso, que o cinema não está fora desse processo. Graves e agudos nos limites da faixa audível pelos ouvidos humanos estão cada vez mais presentes na gravação de sons para cinema, na posterior edição e mixagem, e na recepção nas salas. Há evidentes aumentos também na dinâmica, na relação entre os limites da intensidade sonora e na própria relação sinal-ruído. Tais expansões seriam a pré-condição técnica para a estética sonora contemporânea no audiovisual, que para alguns se caracterizaria como hiperrealista, como nós mesmos já apontamos em trabalhos anteriores.

O que entendemos como central na proposta de Ihde é a defesa de uma necessária filosofia da escuta que ponha em ação uma ontologia do audível, para contrabalançar o ocularcentrismo ao qual já nos referimos. O que mais nos toca como princípio, porém, é a declaração de que uma filosofia da escuta não deve ter como objetivo substituir o espaço dado à visão, e sim entender como essas áreas da percepção se superpõem ou divergem (Ibid.: 15).

Ihde nos parece habilidoso ao demonstrar como as dimensões aural e visual são distintas em nossa percepção (um som escutado e uma imagem vista são de fato fenômenos distintos, assim como um som gravado e uma imagem gravada são fisicamente diferentes), mas se superpõem o tempo todo, produzindo áreas convergentes ou divergentes. Em seu texto há uma série de exemplos, simples em si mesmos, sobre situações do dia a dia nas quais ouvimos muito, enquanto vemos pouco, ou o contrário. Comenta como podemos estar em lugares, por exemplo, escuros, onde não enxergamos, e o quanto ouvimos enquanto não vemos. Cita o paradoxo de Zenão, no qual a divisão do movimento em partes cada vez menores levará ao instante de um não-movimento, para pensar até que ponto um som é audível, ou uma imagem é visível.

Para além dos horizontes possíveis do que se vê, nos interessa aqui, dentro do mapeamento realizado por ele das regiões perceptíveis ou não, a relação entre audível e inaudível. Ihde atesta que o horizonte do som é o silêncio, quando um objeto que nos parece mudo se faz, paradoxalmente, presente. O limite do que escutamos se traduz pelo silêncio. Sua presença se faz sentir e demarca a área da escuta (IHDE, 2007: 50).

Uma fenomenologia do som que tenha a voz como objeto deve ter em conta a centralidade da palavra falada em nosso dia a dia. E, dentro da palavra falada, a centralidade do linguístico, da compreensão semântica do que é dito. Tal entendimento da palavra seria o centro, mas não a totalidade do sentido. Pensando esse centro como um início para a percepção, Ihde propõe pensar: o que descentraliza? O que está em volta do fenômeno de uma palavra falada? Gestos, por exemplo, uma série de manifestações corporais que acontecem em conjunto com o ato de falar. Aqui, mais uma vez, a ancoragem é no corpo. "A linguagem como palavra é normativamente encarnada em som e em voz" (Ibid.: 150).

Com mais espaço em sua argumentação do que os gestos e demais manifestações do corpo, cabe ao silêncio a função de descentralizar o sentido da palavra falada. O silêncio, entendido como horizonte, situa e ao mesmo tempo circunda o espaço do audível. Sobre tudo que é dito e escutado, pairaria o horizonte do que não se escuta. Prestar atenção aos silêncios seria ampliar a área do audível. Seria ouvir entre as palavras (beneath), abaixo (below) da superfície do que é dito. Seria ouvir mais profundo do que se ater ao que aparece na superfície do sentido. A palavra sendo a superfície, o silêncio sendo o que há de mais profundo (Ibid.: 164). 


\section{Considerações finais}

Discorremos aqui sobre três textos principais, com o intuito de expô-los, vindos de áreas diversas como vêm, para que possam servir de embasamento possível ao pensamento atual sobre voz no cinema. Como dissemos no início, não faz parte da proposta deste texto específico aplicar tais conceitos a uma possível análise. Neste momento, apenas apresentamos textos tão importantes quanto pouco lembrados hoje quando pensamos sobre estudos de voz aplicados ao audiovisual.

Temos consciência de que expusemos certas preferências e uma crítica mais clara a um texto do que aos outros dois. Isso obviamente não tem como intenção invalidá-lo. Serve apenas para demarcar como a própria formação intelectual deste pesquisador leva a determinadas discordâncias e a diagnósticos que supõem possíveis contradições entre a eleição de um objeto e a justificativa que se faz para a escolha dele mesmo.

Temos analisado, nos últimos artigos e nas últimas palestras, o cinema contemporâneo e, dentro dele, buscamos diagnosticar nas relações entre as vozes os demais sons e imagens, proposições instigantes a partir da nossa posição de espectador. Seguiremos perseguindo-as, utilizando as ferramentas que encontramos em diversas áreas do conhecimento.

\section{Referências}

BARTHES, R. The grain of the voice. In: STERNE, J. (Ed.). The sound studies reader. New York: Routledge, 2012. p. 504-510.

. Fragmentos de um discurso amoroso. Tradução Isabel Gonçalves. Lisboa: Edições 70, 2015.

DERRIDA, J. The voice that keeps silence. In: STERNE, J. (Ed.). The sound studies reader. New York: Routledge, 2012. p. 495-503.

IHDE, D. Listening and voice: phenomenologies of sound. 2. ed. Albany: State University of New York Press, 2007.

LEVIN, D. M. (Org.). Modernity and the hegemony of vision. Los Angeles: University of California Press, 1993.

MARKS, L. The skin of film. Intercultural cinema, embodiment and the senses. Durham \& London: Duke University Press, 2000.

QUINLIVAN, D. The place of breath in cinema. Edinburgh: Edinburgh University Press, 2012.

STERNE, J. The audible past. Durham; London: Duke University Press, 2003.

WARNKE, G. Ocularcentrism and social criticism. In: LEVIN, D. M. (Org.). Modernity and the hegemony of vision. Los Angeles: University of California Press, 1993. p. 287-308).

ZUMTHOR, P. A letra e a voz. Tradução Amálio Pinheiro e Jerusa Pires Ferreira. São Paulo: Companhia das Letras, 1993. 